\title{
Knowledge and practices of eye health professionals about the availability and accessibility of child eye care services in the public sector in Swaziland
}

\begin{tabular}{|c|c|}
\hline \multicolumn{2}{|c|}{$\begin{array}{l}\text { Authors: } \\
\text { Velibanti Sukati }{ }^{1} \\
\text { Vanessa R. Moodley }^{1} \text { (D) } \\
\text { Khathutshelo P. Mashige }^{1}\end{array}$} \\
\hline \multicolumn{2}{|c|}{$\begin{array}{l}\text { Affiliations: } \\
{ }^{1} \text { Discipline of Optometry, } \\
\text { University of KwaZulu-Natal, } \\
\text { Durban, South Africa }\end{array}$} \\
\hline \multicolumn{2}{|c|}{$\begin{array}{l}\text { Corresponding author: } \\
\text { Velibanti Sukati, } \\
\text { mavegy@gmail.com }\end{array}$} \\
\hline \multicolumn{2}{|c|}{$\begin{array}{l}\text { Dates: } \\
\text { Received: } 01 \text { Aug. } 2018 \\
\text { Accepted: } 04 \text { Mar. } 2019 \\
\text { Published: } 30 \text { July } 2019\end{array}$} \\
\hline \multicolumn{2}{|c|}{$\begin{array}{l}\text { How to cite this article: } \\
\text { Sukati V, Moodley VR, } \\
\text { Mashige KP. Knowledge } \\
\text { and practices of eye health } \\
\text { professionals about the } \\
\text { availability and accessibility } \\
\text { of child eye care services } \\
\text { in the public sector in } \\
\text { Swaziland. Afr Vision Eye } \\
\text { Health. 2019;78(1), a471. } \\
\text { https://doi.org/10.4102/ } \\
\text { aveh.v78i1.471 }\end{array}$} \\
\hline \multicolumn{2}{|c|}{$\begin{array}{l}\text { Copyright: } \\
\text { @ 2019. The Author(s). } \\
\text { Licensee: AOSIS. This wo } \\
\text { is licensed under the } \\
\text { Creative Commons } \\
\text { Attribution License. }\end{array}$} \\
\hline \multicolumn{2}{|l|}{ Read online: } \\
\hline 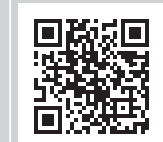 & $\begin{array}{l}\text { Scan this QR } \\
\text { code with your } \\
\text { smart phone or } \\
\text { mobile device } \\
\text { to read online. }\end{array}$ \\
\hline
\end{tabular}

Background: International and African rights instruments stipulate that children have the right to access quality general and eye health care. Lack of access to quality eye care can have a significant negative impact on the child, family and society in general.

Aim: To determine the knowledge and practices of eye care professionals about the availability and accessibility of child eye care services in the public sector in Swaziland.

Setting: The study was conducted in Swaziland.

Methods: This was a quantitative study design, and 15 public eye health professionals completed and returned the Questionnaire for Eye Health Professionals (QEHP).

Results: Thirteen $(86.7 \%)$ eye health practitioners reported that both standard practice guidelines and paediatric national guidelines for ophthalmic services were unavailable. The majority (66.7\%) identified cost and unawareness of available services by parents as the most common barrier to accessing eye care services. Nine (60\%) felt that they were less informed about eye health problems and 6 (40\%) reported being well informed. Eight (53.3\%) respondents indicated that there were no outreach programmes and $7(46.7 \%)$ reported that their clinics offered these services. Thirteen $(86.7 \%)$ eye health practitioners indicated that they were not part of teachers' training for supporting visually impaired children, while 2 (13\%) reported that they were.

Conclusion: Formulation of guidelines to support eye health care service delivery in Swaziland is essential in order to improve availability, accessibility, affordability and effectiveness in the public health system.

Keywords: Swaziland; children's health; public health and education; eye health professionals.

\section{Introduction}

The African continent has high rates of population growth and inadequate health strategies for the provision of efficient health services to its people. ${ }^{1,2}$ It is therefore not surprising that more cases of visual impairment and blindness are reported on this continent, particularly in rural areas. ${ }^{3,4,5}$ Pakenham-Walsh and Bukachi ${ }^{6}$ identified inadequate national health guidelines as the major reason for insufficient knowledge and practice among health workers. Moreover, gaps on awareness and knowledge about clinical or preventative interventions were also noted. Greater knowledge gaps were identified among doctors working in tertiary centres as compared to district hospitals; however, among nurses at different levels, no differences in knowledge gaps were noted. This highlights the need for eye and health policies to address the lack of knowledge across the health care workforce, which may be associated with weak health systems, resulting in a poor performing health care service delivery system.

Research shows that children's eye health is not given adequate attention even though the consequences of poor vision and eye health can have a significantly negative impact on the child, family and society. ${ }^{7,8}$ With an estimated global childhood blindness prevalence of $4 \%-5 \%$, access to child eye health services is important. ${ }^{9}$ The prevalence of blindness in Swaziland is estimated to be approximately $1 \%$ with no specification among children as well as its economic and social burdens. ${ }^{10}$ The population of Swaziland is approximately 1.1 million with $44 \%$ made up of children. ${ }^{11}$ Most of its citizens rely on the public sector for health care services, ${ }^{12,13}$ including eye care. In addition, most of the population live in rural areas with limited or no access to eye care services. 
Eye health is a critical developmental goal for children, and this has a rebound positive impact on the social and economic development of the country. Hence, accessing appropriate eye health services that will ensure their visual health is imperative. Determining the knowledge and practices of eye health professionals about the availability and accessibility of child eye care services in the public health sector in Swaziland will assist in understanding and defining the context within which eye care practitioners work for the development of clear guidelines.

\section{Methods}

A cross-sectional, quantitative design was employed in this study. Validated questionnaires were utilised for eye health care professionals who work in the public sector to determine knowledge and practices in relation to availability and accessibility of child eye care services in Swaziland. According to information from the Ministry of Health, a total of 20 eye health professionals worked in the public health sector and mission clinics in Swaziland during the time of this study. These included optometrists $(n=5)$, an ophthalmologist $(n=1)$, a cataract surgeon $(n=1)$ and ophthalmic nurses $(n=13)$. A saturated sample was used because of few operating eye clinics in the country. Five government eye care facilities, three government hospitals, one non-governmental organisation (NGO) and a church mission clinic were included in this study. Participants were first informed about the purpose of the study before being requested to participate. Written consent forms were signed by each participant after familiarising themselves with the details of the study. Eye clinics were defined as facilities where at least one ophthalmologist or one optometrist works and delivers outpatient consultations, refraction, spectacle dispensing or surgical services. Questionnaires were distributed to all participants and collected in the respective eye clinics throughout the country. A copy of the questionnaire is available on request from the authors. A statistician provided support with the use of appropriate data analysis techniques. Errors and biases were eliminated by ensuring that all questions requiring positive and negative responses were followed by stating reasons why a particular response was chosen. The quantitative data were captured and analysed using the Statistical Package for Social Sciences (SPSS version 24) in consultation with a statistician. Findings are presented as descriptive statistics with tables and graphs.

\section{Ethical considerations}

The study protocol was approved by the Research and Ethics Committee (BE338/13) of the University of KwaZulu-Natal (UKZN) and the Swaziland Health Ethics Committee. Participation was voluntary as stipulated in the University's consent form, and only those who gave written informed consent were allowed to participate in the study. All data captured were kept confidential, and no subject was identified by name.

\section{Results \\ Demographic characteristics of eye health professionals}

A total of 15 questionnaires were completed, giving a response rate of $75 \%$. The respondents included three optometrists, an ophthalmologist and 11 ophthalmic nurses. They included 14 (93.3\%) females and one (6.7\%) male. Eleven $(73.3 \%)$ respondents indicated that none of their relatives wore spectacles. All indicated that none of their children were born blind or had gone blind, and six (40\%) reported taking up to 15 minutes to get to the nearest health facility that offered ophthalmic services. Four (26.7\%) reported taking 16 to $30 \mathrm{~min}$ and 31 to $60 \mathrm{~min}$, while one $(6.7 \%)$ reported that they took more than an hour to get to the health facility that offered ophthalmic services. Five (33.3\%) respondents reported using private cars to reach their workplace and four $(26.7 \%)$ used mini buses or taxis, while three $(20 \%)$ reported using the buses or walked to work. Twelve (80\%) eye health practitioners indicated having access to social media such as Facebook and nine $(60 \%)$ had access to WhatsApp (Figure 1). The majority of eye health practitioners reported that they had access to all mainstream media, with television being the most common $(93.3 \%, n=14)$ followed by newspaper $(80 \%, n=13)$ and radio $(73.3 \%, n=11)$.

\section{Eye care professionals' knowledge about eye care and services}

Fourteen (93.3\%) respondents indicated that there were no guidelines available for standard paediatric optometric referral practices, and only one (6.7\%) reported that they had such guidelines. Those who indicated that there was an absence of guidelines reported poor planning by government and the poor health status in the country. Thirteen $(86.7 \%)$ reported that both standard practice guidelines and paediatric national guidelines for ophthalmic services were unavailable (Table 1). The eye health practitioners suggested the non-prioritisation of eye health compared to other health disciplines as the cause of the lack of both guidelines.

Thirteen (86.7\%) eye health practitioners reported that there were refractive services for children at their workplace (Figure 2). Five (33.3\%) reported that paediatric ophthalmic care and educational services or facilities for the visually

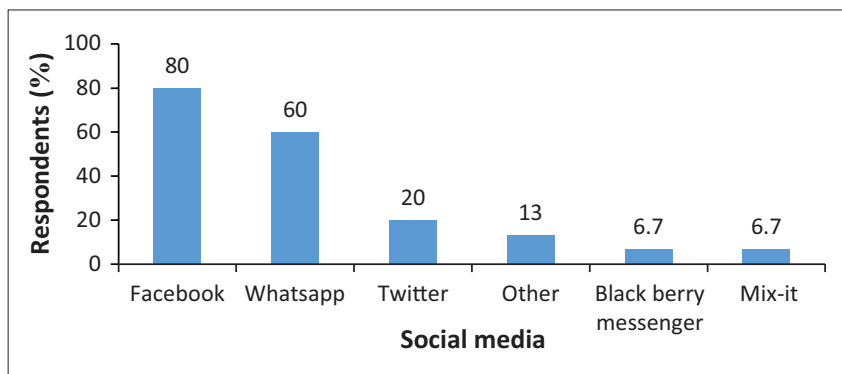

FIGURE 1: Eye health practitioners who reported access to social media ('Other' refers to Skype or the Internet). 
TABLE 1: The percentages of eye health practitioners who reported standard guidelines for paediatric practice $n(\%)$ in relation to national guidelines for referring children.

\begin{tabular}{|c|c|c|c|c|c|c|}
\hline \multirow[t]{3}{*}{ Variable } & \multicolumn{4}{|c|}{ National guidelines } & \multirow{2}{*}{\multicolumn{2}{|c|}{ Total }} \\
\hline & \multicolumn{2}{|c|}{ Yes } & \multicolumn{2}{|c|}{ No } & & \\
\hline & $n$ & $\%$ & $n$ & $\%$ & $n$ & $\%$ \\
\hline \multicolumn{7}{|c|}{ Standard guidelines for paediatric practice } \\
\hline Yes & 0 & 0.0 & 1 & 100.0 & 1 & 100.0 \\
\hline No & 1 & 7.1 & 13 & 92.9 & 14 & 100.0 \\
\hline Total & 1 & 6.7 & 14 & 93.9 & 15 & 100.0 \\
\hline
\end{tabular}

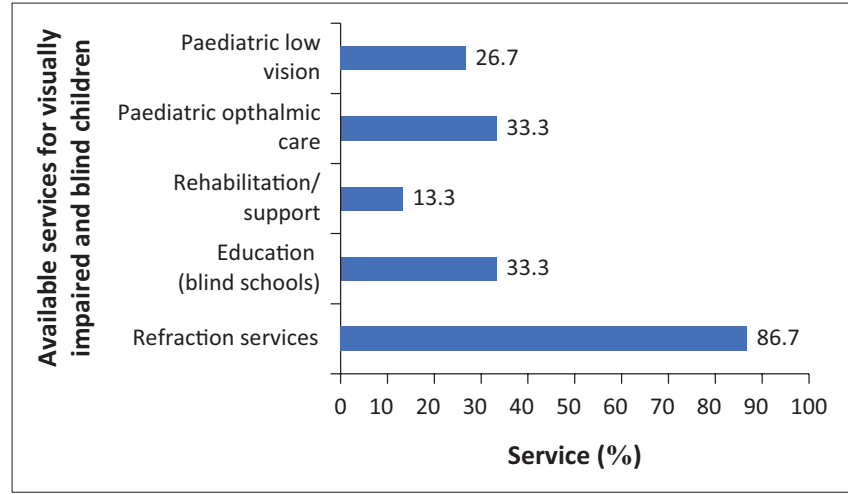

FIGURE 2: Eye health practitioners who reported available services for visually impaired and blind children.

impaired and blind were available, respectively, with other responses being shown in Figure 2.

Ten (66.7\%) eye health practitioners felt that there was a lack of integration between mainstream eye care services and other services, such as rehabilitation, low vision and education. Four (28\%) reported that children requiring eye surgery were funded by government, and $10(66.7 \%)$ noted that parents paid for these expenses. Three (20\%) indicated that funding from NGOs was very low, as were contributions made by missions and parents in the private sector. Fourteen (93\%) respondents stated that no insurance schemes for child eye care were provided; 10 (66.7\%) noted that there was no monitoring of paediatric ophthalmic services, while five $(33.3 \%)$ indicated the use of reports to monitor these services.

Eight (53.3\%) respondents indicated that the indicator frequently used to monitor paediatric services and programmes over 6 months was the number of spectacles dispensed to children following an eye examination. Two $(13.3 \%)$ reported using the number of children who underwent operations as an indicator for monitoring paediatric services, with the other responses being illustrated in Table 2. Ten $(66.7 \%)$ identified cost, distance travelled and unawareness of available services by parents as the most common barriers to accessing eye care services (Table 3). Competing demands for resources was the least identified barrier $(6.7 \%)$, while none of the eye health practitioners indicated language as a barrier.

Fourteen (93.3\%) respondents indicated that rural children were less likely to access eye care services, 11 (73.3\%) noted that children from low-income backgrounds were less likely
TABLE 2: Eye health practitioners who reported indicators used to monitor paediatric services and programmes.

\begin{tabular}{lll}
\hline Indicator & $\boldsymbol{n}$ & $\mathbf{\%}$ \\
\hline Number of refracted children & 5 & 33.3 \\
Number of children attending services & 7 & 46.7 \\
Number of operated children & 2 & 13.3 \\
Number of children dispensed glasses & 8 & 53.3 \\
Number of paediatric cases seen & 6 & 40.0 \\
None & 2 & 13.3 \\
\hline
\end{tabular}

$n=15$.

TABLE 3: Eye health practitioners who reported barriers to accessing eye care services by children.

\begin{tabular}{lcc}
\hline Barrier & $\boldsymbol{N}$ & $\mathbf{\%}$ \\
\hline Parent believe nothing can be done & 4 & 26.7 \\
Language & 0 & 0.0 \\
Culture and tradition & 3 & 20.0 \\
Fear of hospitals and outcomes & 3 & 20.0 \\
Competing demands for resources & 1 & 6.7 \\
Cost & 10 & 66.7 \\
Distance travelled & 7 & 46.7 \\
Parents unaware that something can be done & 7 & 46.7 \\
\hline$n=15$. & &
\end{tabular}

to access eye care services and $6(40 \%)$ identified children living with multiple disabilities as less likely to access them. None of the respondents identified gender as a barrier to accessing eye care. Nine (60\%) felt that they were less informed about eye health problems, and six (40\%) reported being well informed. Ten $(66.7 \%)$ believed that children born blind or living with visual impairment do not have the same opportunities as normal children. Three (20\%) felt that visually impaired or blind children have equal opportunities as 'normal' sighted children, and two (13.3\%) were unsure.

Fourteen (93\%) reported that most children presented with allergic conjunctivitis, and seven $(46.7 \%)$ reported that most children presented with refractive error (RE). Both corneal injuries and vitamin A deficiency (VAD) were the least reported conditions that children presented with (Figure 3).

Regarding strategies to prevent childhood blinding diseases, $11(73.3 \%)$ suggested the use of awareness campaigns, nine $(60 \%)$ suggested encouraging eye testing at an early age, seven $(46.7 \%)$ suggested school screening and one $(6.7 \%)$ was not sure. Thirteen $(86.6 \%)$ respondents felt that hospitals were not doing enough to address childhood blinding diseases. The lack of equipment $(66.7 \%, n=10)$ and skilled personnel $(60 \%, n=9)$ were the most frequently reported by the eye health practitioners. However, 12 (80\%) eye health practitioners reported that their clinics examined children, and three $(20 \%)$ indicated that they did not, regardless of the lack of equipment and skilled personnel. Ten (66.7\%) indicated that they requested children to present every 6 months, and five $(33.3 \%)$ preferred yearly visits. Out of a range of possible causes of poor vision in children, 14 (93\%) identified eye conditions with hyperopia (26.7\%) and myopia $(20 \%)$ as being possible causes. None of the respondents indicated reading, television, computer games and headache as possible causes of poor vision. 


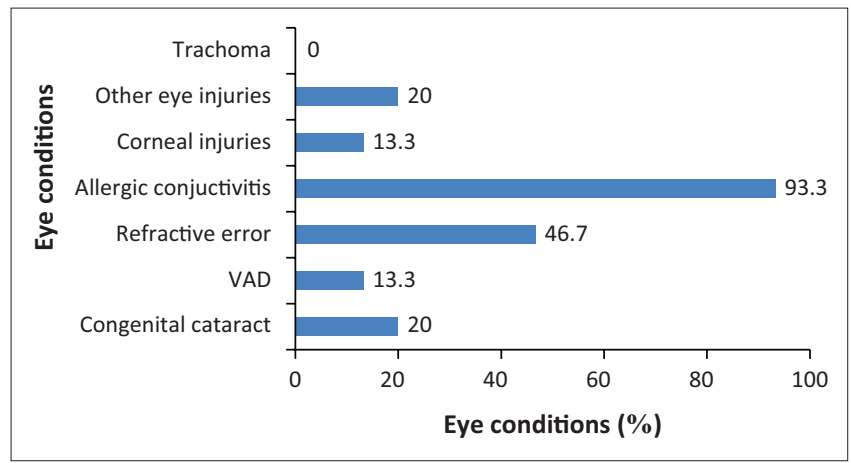

FIGURE 3: Eye health practitioners who reported conditions that children presented with at the eye clinics.

Nine $(60 \%)$ respondents indicated that they advised parents to test their children's eyes every 6 months. Three (20\%) advised 3- and 6-year eye testing intervals, and 11 (73.3\%) indicated offering advice to test children before schooling. Thirteen $(86.7 \%)$ eye health practitioners advocated the use of radio, $10(67 \%)$ civil society campaigns and nine $(60 \%)$ both newspaper and television for spreading information about available eye health services. All the respondents agreed that spectacles did not make the children's vision worse. Fourteen (93\%) suggested that children presenting to hospitals should wear spectacles for RE correction when required, and a similar number reported being in favour of conducting paediatric eye testing.

\section{Eye care professionals' practices about eye care}

Eight $(53.3 \%)$ respondents indicated that there were no outreach programmes, and seven $(46.7 \%)$ reported that their clinics offered outreach programmes. Furthermore, three $(20 \%)$ indicated that their clinics had conducted outreach in less than a year, and six $(40 \%)$ noted that their outreach programmes offered health and eye care services. Five (33.3\%) reported that outreach programmes took place in their communities, but that none of the programmes were aimed at detecting and treating VAD. Thirteen $(86.7 \%)$ of the respondents indicated that they were not part of teachers' training for supporting visually impaired children, while two $(13 \%)$ reported that they were.

\section{Discussion}

\section{Demographic profiles}

The majority of eye care professionals were females, which could be because of the fact that the majority of eye health professionals who responded were ophthalmic nurses, with nursing being a female-dominated profession in Swaziland. Many eye care practitioners had access to social and mainstream media, and these platforms can be utilised for sharing information, such as new cases seen in clinical settings, emerging research in eye health and distributing eye heath information. In 2008, the Central Statistical Office and Macro International reported that $97 \%$ of the population in Swaziland is African, which is in line with the race group working in the public service. The majority of the eye care professionals' family members did not wear spectacles, which could be because of the fact that their children have had eye examinations and did not need spectacles, and none of the children were reported to be blind or visually disabled. Many eye care professionals took less time to reach the nearest eye doctor or optometrist. This may be attributed to the fact that most are provided with accommodation within the vicinity of the hospital premises. This result could also have been influenced by the fact that these professionals used private transport with a few using buses and walking to the nearest eye care facility.

\section{Knowledge of eye health professionals about eye care and services}

The eye health professionals reported a lack of national paediatric referral guidelines and standard paediatric ophthalmic practice guidelines. The lack of information on epidemiological data on childhood eye conditions in the country impacts negatively on children, as no preventative initiatives can be implemented. This may be as a result of the poorly drafted National Health Policy (2006), which, in its current state, does not provide adequate information to develop an eye health care policy for the levels of services. Borrel et al. ${ }^{7}$ suggested that poor countries struggle to advance better health policies, suggesting the need for health education in schools. Eye health professionals reported that refractive services were prioritised over other services such as rehabilitation and education, which may be because of the chronic shortage of skilled personnel and equipped clinics that rehabilitation services require. This could also be because of the fact that refractive services are the dominant services provided to children. The development of an eye health policy integrating services, human resource recruitment and equipment is warranted. Furthermore, there is a need to formulate a professional association or board for eye health professionals to take the lead on eye health issues in the country.

Access to any health care system is more likely to be complex ${ }^{8,14}$; hence, out-of-pocket payments because of a lack of sufficient health insurance may influence the decision to seek eye care. The low funding from NGOs, missions and government, as indicated by the respondents, may not only reflect that eye health care is not prioritised but also show the lack of information on eye conditions affecting children in the country. These impact negatively on children living with visual disabilities because of limited access to appropriate ophthalmic services offered at clinic level and outreach programmes. Njepuome et al. ${ }^{15}$ also suggested that the lack of finances and human resources to perform the necessary procedures are major challenges in developing countries. The respondents acknowledged that the lack of insurance schemes for child eye care services hinders access to ophthalmic facilities, as eye care interventions are expensive because treatment sometimes requires multidisciplinary interventions. This may prompt parents with children suffering from chronic eye conditions or in need of ophthalmic services to seek intervention elsewhere (such as a traditional healer) than at eye health facilities, because they are expected 
to pay at every visit when taking children for vision testing. The lack of government policies, particularly in developing countries, contributes to the unaffordability of eye care services. ${ }^{8,16}$ These issues need to be addressed through eye health education for parents and children by the Health Ministry, and innovative approaches explored to ensure sustainable funding for child eye health care needs. A joint venture including the government, NGOs and private sector is necessary for scaling up initiatives that will ensure children access eye health services without their parents being burdened with costs of care. Moreover, insurance schemes need to be made available for children needing tertiary services, particularly across the border in South Africa, for which they will have to pay.

The lack of data on childhood blindness leads to poor planning, as indicated in a report by Gilbert et al., ${ }^{17}$ to identify what most children present with and the consequences, thereby highlighting the different levels of socio-economic status and health care provision. The Swaziland government needs to prioritise eye health care by advocating research and training for eye health professionals, which will provide evidence-based data to plan for improving children's eye health visual status. The finding on monitoring indicators of paediatric services in the study reiterates the point that refractive services are given priority over other ophthalmic services. However, these findings highlight that eye clinics use different indicators for monitoring purposes, which has shortcomings, as other indicators are ignored. Studies investigating the barriers to eye health care have identified the cost of the actual operation, accessibility and knowledge of services, cultural and social barriers, as well as trust in the outcome of the operation, ${ }^{18,19}$ these results being similar to those of this study.

The results showed that poor and rural children had limited access to eye health. Madden et al..$^{20}$ also reported that people from rural areas and low-income families experience low access to eye health facilities and are more exposed to eye diseases that cause visual impairment. This is compounded by the lack of an eye health policy to guide eye health services delivery in Swaziland. Jones ${ }^{21}$ reiterated that some countries have drafted policies on disabled children that are enshrined in their constitutions; however, these policies are not effectively implemented, because children are expected to pay to gain access to health facilities. Forming a committee to source funding and ensure technical commitment to eliminate visual impairment and blindness in children is therefore warranted.

In 2012, Pons et al. ${ }^{10}$ found that children seen at one of the clinics in Swaziland presented with childhood blinding conditions such as RE and VAD. The eye health professionals in this study indicated allergic conjunctivitis as being the most common condition. This may indicate the low RE prevalence in African countries, as reported by Wedner et al.,22 as well as the reduced levels of VAD, with most children presenting to eye clinics having been vaccinated at an early age. Eye injuries and congenital cataracts were also reported suggesting the need to conduct workshops on eye health for eye health practitioners to close the knowledge-practices gap among them regarding priority conditions and their management, as well as to improve service delivery.

The respondents cited the use of awareness campaigns as one of the most effective strategies to prevent childhood blinding diseases. It is therefore important to identify the relevant media to be utilised which will enable parents and children in rural and remote areas to be reached. It is expected that with the lack of eye health personnel and equipment, eye clinics were reported to be failing to address childhood blinding diseases. This is similar to reports by Gilbert et al. ${ }^{18}$ and Jadoon et al. ${ }^{23}$ The negative consequences expected in such clinic conditions may extend from misdiagnoses of children, providing wrong advice to prescribing inappropriate medication. The varying views on when children should present for an eye examination represent a barrier to eye health. There may be a gap in knowledge and practice among the eye health practitioners as some may not know what to say or do when a child presents to the clinic. The lack of knowledge may lead to eye health practitioners not following paediatric clinical guidelines when attending to children. Gaps on awareness and knowledge about clinical or preventative interventions were also noted by PakenhamWalsh and Bukachi. ${ }^{6}$ Formulating an eye health signatory body to advance continuing professional developmental (CPD) programmes and foster compliance on minimum standards for children's examination appears paramount. Demanding tasks can cause visual problems as children utilise the sense of sight the most in school. Salomao et al. ${ }^{24}$ reported that the more academic work done and the high expectations on educational achievement increase the risk of myopia development. Developing strategies to inform eye health practitioners on the causes of poor vision is therefore essential.

The provision of corrective measures to children has been highlighted in many reports, ${ }^{22,25,26}$ especially in developed countries. ${ }^{25}$ Some may argue that it is not correct to prescribe glasses to children as their eyes are still not fully grown. ${ }^{26}$ Consequently, those who have visual impairment will live with it for many years before it is identified. An important issue raised by eye care professionals was that they felt that they were not well informed about eye health problems. Frazier and Kleinstein ${ }^{8}$ also reported in their study that some eye health practitioners did not know what needed to be done when children present to the hospital. This suggests the need for capacitating the current eye health workforce through CPD programmes.

\section{Practices of eye care professionals about eye care}

Resource constraints, including personnel and equipment which are scarce in the country, hinder the provision of outreach programmes in communities and public schools. ${ }^{12,13}$ This is prone to have a negative impact as it 
disadvantages children living in poorly resourced areas from accessing eye health services timeously. Of concern is that the frequency of conducting outreach programmes was very low as a result of resource constraints as reported by eye health professionals who indicated being involved in such activities which further compromise timeous intervention. Decentralising eye health services with equitable staff deployment to areas where eye health services are not available is essential, and health workers who understand the regional constructs of the community they serve can be roped in to conduct eye health education in communities. The absence of VAD outreach programmes as reported by eye health professionals may increase the mortality rate and corneal blindness. This aligns with a report by Lewallen and Courtright ${ }^{1}$ suggesting that poor countries fail to identify vitamin A deficient children and provide enough immunisation to prevent the disease. Therefore, understanding the socio-economic status and health resource constraints that are prone to dividing aid for the eradication of VAD are paramount. Fortunately, all issues pertaining to the prevention and child-integrated immunisation are enshrined in the Sustainable Development Goals (SGDs) for children which priorities with the hope that no child will go blind from VAD in Swaziland. ${ }^{12,13}$

Most eye care professionals reported that they were not involved in training teachers to identify, screen and support children with visual impairment. Resource constraints such as personnel and equipment are the main factors contributing to the non-involvement of health staff in teachers' training. The Education and Health Ministries need to prioritise teacher training to help relieve eye health professionals' workloads as suggested by Powell et al..$^{27}$ and Korani et al. ${ }^{28}$ The majority of eye health professionals preferred the use of mainstream media and campaigns to reach out to parents on vision problems affecting their children. However, it is important to ensure that such initiatives reach all areas, particularly rural and remote areas.

Possible limitations of our study include the focus on availability and accessibility of child eye health for children in the public sector only. The study also relied on responses from eye care professionals in the public sector only. In addition, the influence of culture, beliefs and attitudes on availability and accessibility to child eye health requires further investigations.

\section{Conclusion}

The survey of eye health professionals offers a situational analysis of the eye health delivery system, challenges encountered, knowledge inadequacy, barriers to ophthalmic services and suggestions on how public eye health services can be improved. Drafting guidelines on eye health and adhering to them is important to improve service delivery. Conducting research and identifying monitoring indicators for regular evaluations may directly improve eye health.

\section{Acknowledgements Competing interests}

The authors declare that they have no financial or personal relationships that may have inappropriately influenced them in writing this article.

\section{Authors' contributions}

This article forms part of the $\mathrm{PhD}$ thesis undertaken by V.S., supervised by V.R.M. and K.P.M.

\section{Funding information}

The study received an operation stipend from the University of KwaZulu-Natal.

\section{Data availability statement}

Data sharing is not applicable to this article.

\section{Disclaimer}

The views and opinions expressed in this article are those of the authors and do not necessarily reflect the official policy or position of any affiliated agency of the authors.

\section{References}

1. Lewallen S, Courtright P. Blindness in Africa: Present situation and future needs. Br J Ophthalmol. 2001;85(8):897-903. https://doi.org/10.1136/bjo.85. 8.897

2. Oduntan AO. Prevalence and causes of low vision and blindness worldwide. S Afr Optom. 2005;64(2):44-54. https://doi.org/10.4102/aveh.v64i2.214

3. Adala HS. Ocular injuries in Africa. Soc Sci Med. 1983;17(22):1729-1735. https:// doi.org/10.1016/0277-9536(83)90384-2

4. Gyasi ME, Adjuik MA, Amoaku WMK. Epidemiology of hospitalized ocular injuries in the Upper East Region of Ghana. Ghana Med J. 2007;41(4):171-175.

5. Bejiga A. Causes and visual outcomes of perforating ocular injuries among Ethiopian patients. Com Eye Health. 2001;14(39):45-46.

6. Pakenham-Walsh N, Bukachi F. Human resources for health information needs of health care workers in developing countries: A literature review with a focus on Africa. Hum Resour Health. 2009;13:1-13.

7. Borrel A, Dabideen R, Mekonen Y, Overland L. Child eye health in Africa. The status and way forward. The African Child Policy Forum. Cape Town, South Africa: ORBIS Africa. 2013; p. 1-37.

8. Frazier M, Kleinsten R. Access and barriers to health care, Optometric Care within the Public Health Community. Cadyville, NY: Old Post Publishing. 2009; p. 1-19.

9. Siddiqui R. Manavseva crusade against childhood blindness. INGOJ. 2009;4(5): 253-255.

10. Pons J, Mapham W, Newsome B, et al. The potential impact of a cataract surgery programme on the care of orphans and vulnerable children in Swaziland. S Afr Med J. 2012;102(3):140-141. https://doi.org/10.7196/SAMJ.5568

11. Central Statistical Office \& Macro International. Government of the Kingdom of Swaziland; 2008.

12. World Bank. Swaziland public expenditure review: Strengthening public expenditure policy and management for service delivery and poverty reduction. Washington, DC: World Bank. 2006.

13. Ministry of Health and Social welfare. National Health Policy. Government of the Kingdom of Swaziland. 2006.

14. MacKinney C, Coburn AF, Lundblad JP, McBride TD, Mueller KJ, Watson SD. Access to rural health care $-A$ literature review and new. RUPRI Health Panel. 2014:1-22.

15. Njepuome N, Onyebuchi $U$, Onwusoro $M$, Igbe $M$. Visual impairment among public servants in Abuja, Nigeria. J Ophthalmol Vis Sci. 2012;9(1):14-18.

16. Shirima SB, Geneau R. Why are children with cataracts brought late for surgery? Qualitative findings from Tanzania. Kilimanjaro Centre for Community Ophthalmology; 2006. 
17. Gilberti CE, Canovas R, Hagan M, Fosteri A. Causes of childhood blindness: Results from West Africa, South India and Chile. Eye. 1993;7:184-188. https://doi.org/ 10.1038/eye.1993.39

18. Jadoon Z, Shah SP, Bourne R, et al. Cataract prevalence, cataract surgical coverage and barriers to uptake of cataract surgical services in Pakistan: The Pakistan National Blindness and Visual Impairment Survey on behalf of the. Br J Ophthalmol. 2007;91:1269-1273. https://doi.org/10.1136/bjo.2006.106914

19. Sapkota YD, Sunuwar M, Naito T, Akura J, Adhikari HK. The prevalence of blindness and cataract surgery in Rautahat District, Nepal. Ophthalmic Epidemiol. 2010;17(2) 82-89. https://doi.org/10.3109/09286581003624947

20. Madden AC, Simmons D, McCarty CA, Khan MA, Taylor HR. Eye health in rura Australia. Clin Exp Ophthalmol. 2002;30:316-321. https://doi.org/10.1046/j. 1442-9071.2002.00549.x

21. Jones H. Disabled children's rights and the UN convention on the rights of the child. Dis Stud Q. 2000;20(4):11-15. https://doi.org/10.18061/dsq.v20i4.266

22. Wedner S, Masanja H, Bowman R, Todd J, Bowman R, Gilbert C. Two strategies for correcting refractive errors in school students in Tanzania: Randomised comparison, with implications for screening programmes. Br J Ophthalmo 2008;92(1):19-24. https://doi.org/10.1136/bjo.2007.119198
23. Gilbert CE, Shah SP, Jadoon MZ, et al. Poverty and blindness in Pakistan: Results from the Pakistan National Blindness and Visual Impairment Survey. Br Med J. 2008;336(7):29-32. https://doi.org/10.1136/bmj.39395.500046.AE

24. Salomão SR, Mitsuhiro MR, Belfort R, Jr. Visual impairment and blindness: An overview of prevalence and causes in Brazil. Invest Ophthalmol Vis Sci. 2009;50(9):4114-4120. https://doi.org/10.1590/S0001-3

25. Congdon NG, Patel N, Esteso P, et al. The association between refractive cutoffs for spectacle provision and visual improvement among school-aged children in South Africa. Ophthalmology. 2008;116(5):1009-1002.

26. Oduntan AO, Raliavhegwa $\mathrm{M}$. An evaluation of the impact of the eye care services delivered to the rural communities in the Mankweng Health sub-district of the Northern Province of South Africa. S Afr Optom. 2001;60(3):71-76.

27. Powell C, Wedner S, Hatt SR. Vision screening for correctable visual acuity deficits in school-age children and adolescents. Cochrane Database Syst Rev. 2004;4:CD005023. https://doi.org/10.1002/14651858.CD005023.pub2

28. Korani J, Williams JD, Rose A, Khanna R. A prospective study to assess the quality of preliminary eye screening done on school children by teachers in Andhra Pradesh. J Com Med Health Educ. 2015;5(2):1-5. https://doi.org/10.4172/2161 0711.1000342 